\title{
HazMapper: a global open-source natural hazard mapping application in Google Earth Engine
}

\author{
Corey M. Scheip ${ }^{1,2}$ and Karl W. Wegmann ${ }^{1,3}$ \\ ${ }^{1}$ Department of Marine, Earth, and Atmospheric Sciences, North Carolina State University, Raleigh, NC 27695, USA \\ ${ }^{2}$ North Carolina Geological Survey, Division of Energy, Mineral, and Land Resources, \\ Department of Environmental Quality, Swannanoa, NC 28778, USA \\ ${ }^{3}$ Center for Geospatial Analytics, North Carolina State University, Raleigh, NC 27695, USA
}

Correspondence: Corey M. Scheip (cmscheip@ncsu.edu)

Received: 2 April 2020 - Discussion started: 29 April 2020

Revised: 24 March 2021 - Accepted: 26 March 2021 - Published: 12 May 2021

\begin{abstract}
Modern satellite networks with rapid image acquisition cycles allow for near-real-time imaging of areas impacted by natural hazards such as mass wasting, flooding, and volcanic eruptions. Publicly accessible multi-spectral datasets (e.g., Landsat, Sentinel-2) are particularly helpful in analyzing the spatial extent of disturbances, however, the datasets are large and require intensive processing on high-powered computers by trained analysts. HazMapper is an open-access hazard mapping application developed in Google Earth Engine that allows users to derive map and GIS-based products from Sentinel or Landsat datasets without the time- and cost-intensive resources required for traditional analysis. The first iteration of HazMapper relies on a vegetation-based metric, the relative difference in the normalized difference vegetation index (rdNDVI), to identify areas on the landscape where vegetation was removed following a natural disaster. Because of the vegetation-based metric, the tool is typically not suitable for use in desert or polar regions. HazMapper is not a semi-automated routine but makes rapid and repeatable analysis and visualization feasible for both recent and historical natural disasters. Case studies are included for the identification of landslides and debris flows, wildfires, pyroclastic flows, and lava flow inundation. HazMapper is intended for use by both scientists and non-scientists, such as emergency managers and public safety decision-makers.
\end{abstract}

\section{Introduction}

Natural disasters such as landslides, wildfires, and volcanic eruptions are a primary mechanism of landscape change (Korup et al., 2010; Santi et al., 2013) while simultaneously causing fatalities into the 21st century (Froude and Petley, 2018; Petley, 2012; Auker et al., 2013; Holzer and Savage, 2013; Ashley and Ashley, 2008). As such, both Earth scientists and emergency managers have a keen interest in understanding natural disaster occurrences and their spatial extent. Ongoing work to increase predictive capabilities for natural hazard events (Goetz et al., 2015; Guzzetti et al., 2006) rely on the robust characterization (e.g., number or spatial distribution of landslides) of modern-day events (Xu et al., 2016; Gallen et al., 2017).

Readily observable field evidence of only the largest or most recent natural disasters typically persists in temperate environments due to the constant regrowth cycle of vegetation. Locating this field evidence and determining historical patterns of natural disasters is a primary objective for many agencies and communities (Paton and Johnston, 2001; Wegmann, 2006; Brand et al., 2019). However, fieldwork is often inefficient and expensive compared to remote sensing methods and it does a poorer job at temporally constraining natural disasters. For example, the timing and extent of a series of landsliding events over many years will be difficult and expensive to determine with field methods alone. In addition, field-verified inventories of spatially extensive events may take many months to years before their completion. In this case, remote sensing methods may be able to temporally 
discern the cycle of events (Gold, 2004) and reduce the lag time between event occurrence and inventory development.

The advent of rapid-repeat-cycle satellite datasets (e.g., multi-spectral, thermal) revolutionized the field of remote sensing and our ability to observe landscape changes. These data have been utilized since the 1970s (e.g., Landsat) to observe, monitor, and track landscape change (Lauer et al., 1997). In 2008, NASA began offering Landsat datasets for free to the general public via the internet (Woodcock et al., 2008), and by now, the entire archive is available online. Subsequent satellite networks and payloads (e.g., Moderate Resolution Imaging Spectroradiometer - MODIS, Sentinel) have improved capabilities, and increasingly advanced satellite networks continue to be developed (e.g., Hoffman et al., 2016; Langhorst et al., 2019). Some traditional uses for satellite observations include identifying landslides and debris flows (e.g., Tillery and Rengers, 2019), identifying wildfire (e.g., Miller and Thode, 2007; Amos et al., 2019), volcanic monitoring (e.g., Cando-Jácome and MartínezGraña, 2019), identifying deforestation (e.g., Hansen et al., 2013; Green and Sussman, 1990; USGS, 2019), identifying urban change and development (e.g., Masek et al., 2000; Schneider, 2012), and ecological monitoring and change detection (e.g., Zhou et al., 2001; Meentemeyer et al., 2004), among others.

Analysis of remote sensing data has traditionally been performed by trained analysts on high-powered computers, which can create a resource barrier for fiscally strained communities or those without advanced training. Combining the open-access nature of these datasets with modern computational power available via cloud computing is a recent development that has powerful implications for natural disaster monitoring (Kirschbaum et al., 2019). Google Earth Engine is a remote sensing data analysis platform designed to take advantage of Google's infrastructure for data storage, access, processing, and visualization (Gorelick et al., 2017).

HazMapper (Hazard Mapper) is an open-access application developed in Google Earth Engine for the rapid characterization of natural disasters tailored to both the scientific and the emergency management communities (Fig. 1). HazMapper is useful for monitoring landscape change that results in the removal or recovery of terrestrial vegetation associated with a natural disaster or human activities. The platform is not currently suitable for use in non-vegetated environments (e.g., polar, high-altitude, or desert regions).

While the underlying mathematics are not novel, HazMapper democratizes multi-spectral satellite data processing for the evaluation of natural hazards by leveraging the accessibility and computational power of Google Earth Engine. Select case studies are discussed here and include both rainfall and seismically triggered mass wasting, wildfire, pyroclastic flow, and landscape burial by lava flows resulting from a fissure eruption. In the aftermath of large natural disasters, the level of emergency response can vary based on available resources for the region or country. For example, re- sponse efforts for a large landslide disaster in the United States, (e.g., 2014 Oso landslide, WA, or 2019 Montecito, $\mathrm{CA}$, debris flows) can garner the attention and resources of local, state, and federal government agencies (Scholl and Carnes, 2017). In less affluent regions, however, response efforts may be less intensive and timely, risking increased loss of life. An overarching goal of HazMapper is to leverage rapid scientific analysis and computing tools for global natural hazard awareness. HazMapper is publicly accessible at https://hazmapper.org/ (last access: 29 April 2021).

\section{Design principles}

Traditional GIS analysis consisting of downloading satellite images and processing on local machines has several limitations in the modern computing environment. These limitations are exacerbated when attempting to perform spatially expansive analysis, such as identifying far-field effects of a natural disaster (e.g., analyzing hundreds of kilometers around an earthquake's epicenter for coseismic mass wasting). Further, the potential need to observe many pre- or post-event images due to challenges such as cloud cover or atmospheric aerosols can hinder this workflow by requiring the analyst to repeat the data download-process routine. This fixed-extent processing routine inhibits the analyst from exploring impacts without stopping analysis to download and process additional data.

In the context of these limitations, HazMapper was developed in Google Earth Engine because the platform provides some key advantages compared to traditional downloadprocess routines. For example, the platform's architecture initiates geospatial processing updates as the user navigates the map. Because of this feature, HazMapper can be used to quickly evaluate spatially expansive hazards by panning or zooming without downloading any data. The source code for HazMapper initiates data processing on remote servers without requiring any specialized or licensed software and can be performed on any internet-connected device. Typical processing times on HazMapper are less than 1-2 min, allowing users to adjust variables and visualization parameters to rapidly assess the potential impact of natural hazards at a specific location or across a region of interest and to test hypotheses about the spatial and temporal extent of a natural hazard event. Google Earth Engine allows users to create public-facing applications (such as HazMapper), further increasing the accessibility of processing routines to specialists in the field as well as to the scientifically curious public.

HazMapper is designed around user-input variables in a graphical user interface (GUI). The user is able to modify the following variables: dataset selection (Landsat 7, Landsat 8, Sentinel-2), event date, pre-event time window, postevent time window, maximum cloud cover for analysis, and slope thresholds (Table 1). These variables can be updated throughout the use of the tool to aid in identifying hazard- 


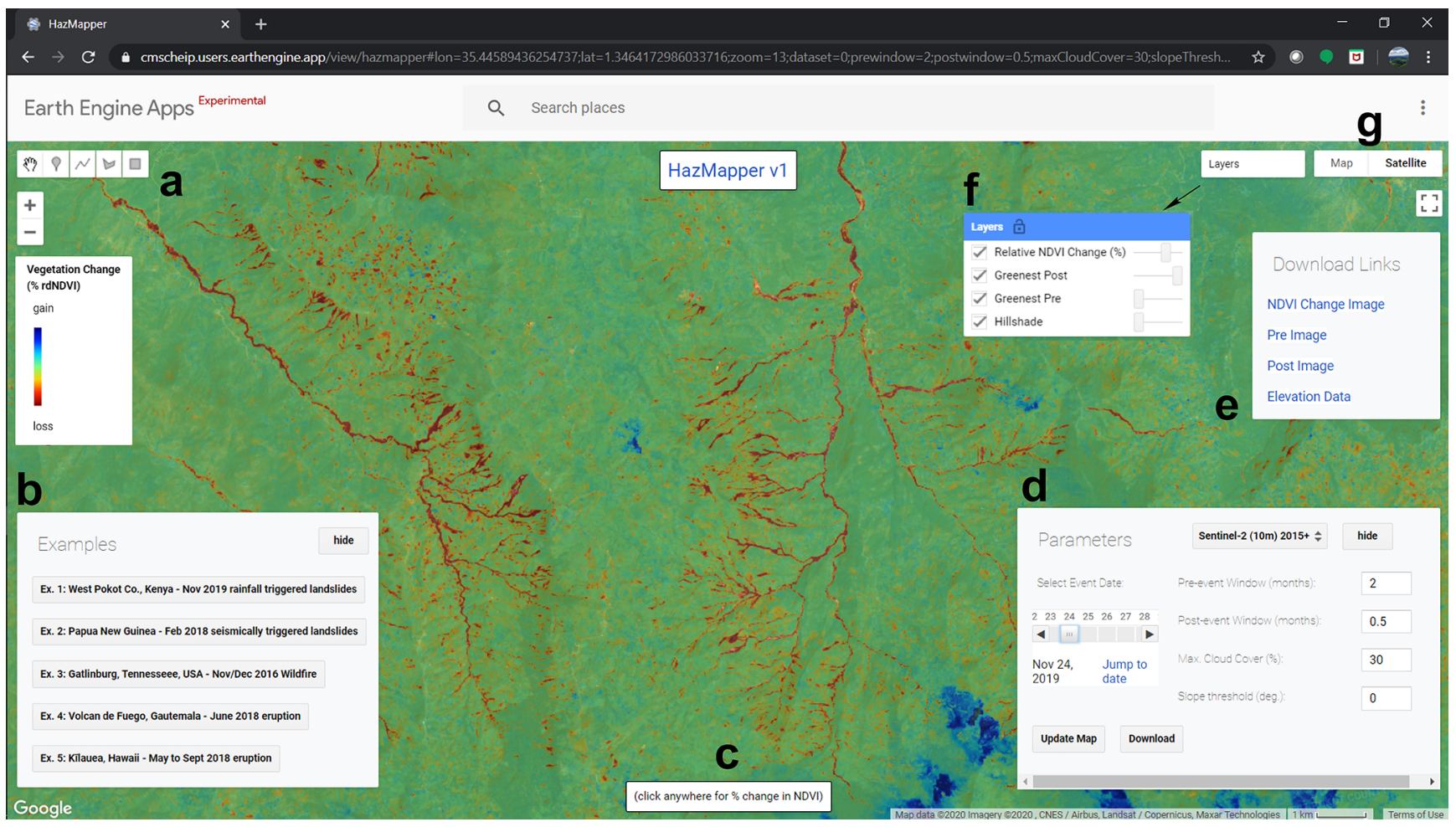

Figure 1. User interface of the HazMapper application in Google Earth Engine. Moving counterclockwise around the interface: (a) digitization tools allow the user to digitize features of interest as points, lines, or polygons. (b) An example window allows users to explore five curated examples. Data on this map show results from Example 1: November 2019 rainfall-triggered mass wasting, West Pokot County, Kenya. (c) Users can display rdNDVI (relative difference in the normalized difference vegetation index) results from a single point by clicking at a location on the map. The displayed result is in the format "(latitude, longitude), rdNDVI result." (d) The parameters window allows users to select the various input values, as further explained in Table 1 and Sect. 4.2 of the Discussion. This panel also contains the Download button, which initiates the population of download links as seen in E. The Update Map button will restart data processing following user modification of the event parameters. (e) Download links for the resulting datasets allows users to save data directly to their local disk for further analysis and processing as desired. If any digitized geometries are present, a digitized-geometries link will allow users to save a Google Earth-compatible keyhole markup language (KML) file. (f) The Layers pane contains four consistent layers, including a hillshade DEM, the greenest composite pre- and post-event pixel images, and the rdNDVI image. Users can choose to turn on/off each layer as well as to adjust the layer transparency. (g) The default basemaps available in Google Earth Engine include satellite imagery with or without labels and a standard borders map with or without terrain data. Notice that the URL reflects current HazMapper parameters. URLs are automatically updated during use of the app. This design feature facilitates sharing of finds in HazMapper among colleagues by simply copying and pasting the URL into an email or instant message chat screen, for example.

stricken locations. The basemap options are Google's global terrain or satellite imagery. The resulting data layers are displayed in a layers pane, available for toggle and transparency adjustment.

Traditional remote-sensing-based landslide mapping is performed by analysts observing change in aerial photographs (e.g., Malamud et al., 2004; Wegmann, 2006; Abancó et al., 2020). This method relies on single pre- and post-event scenes and is hampered when unfavorable atmospheric conditions exist. In the immediate aftermath of natural hazards that are initiated atmospherically (e.g., rainfalltriggered mass wasting) or volcanically (e.g., eruptions), it is not uncommon for imagery to be obscured by clouds or ash plumes, respectively. In cases of tropical or subtropical cyclones, cloud cover may persist for days to weeks following a disaster. Additionally, tropical regions of elevated rainfall and topography, thus typical of mass wasting or flooding hazards, may experience cloud cover for a substantial portion of the annual climate cycle.

To overcome potentially opaque atmospheric conditions that might be caused by aerosols including water vapor (clouds), smoke, mineral matter (dust), or anthropogenic pollution (smog), HazMapper capitalizes on a technique within Google Earth Engine to generate and perform calculations on a greenest-pixel composite (Fig. 2). The compositing method utilizes data from many images, reducing artifacts present from clouds and other aerosol particles in a given single image. The greenest-pixel composite is a single composite or tiled image generated from all images within the user-defined pre- and post-event window that records the pixel with the 
Table 1. HazMapper input variables, definitions, and examples.

\begin{tabular}{llc}
\hline Input variables & Definition & Example \\
\hline Dataset & Dataset to use for analysis, currently Landsat 7, Landsat 8, or Sentinel-2 & Sentinel-2 (10 m) 2015+ \\
\hline Event date & Date of storm, earthquake, weather event, etc. & 9 December 2016 \\
\hline Pre-event window & $\begin{array}{l}\text { The number of months to use for observing the greenest pixel-by-pixel } \\
\text { conditions prior to the event }\end{array}$ & 12 \\
\hline Post-event window & $\begin{array}{l}\text { The number of months to use for observing the greenest pixel-by-pixel } \\
\text { conditions following the event }\end{array}$ & 3 \\
\hline $\begin{array}{l}\text { Maximum cloud } \\
\text { cover }\end{array}$ & $\begin{array}{l}\text { The maximum percentage of a scene obscured by clouds and still used } \\
\text { in the analysis; the cloud-cover percent is embedded in the metadata for } \\
\text { each Landsat or Sentinel scene }\end{array}$ & 30 \\
\hline Slope threshold & $\begin{array}{l}\text { A minimum topographic slope value in degrees, less than which will be } \\
\text { omitted from the data visualization; this is helpful to remove water bodies } \\
\text { like lakes and adjacent oceans in coastal regions }\end{array}$ & 0.01 \\
\hline
\end{tabular}

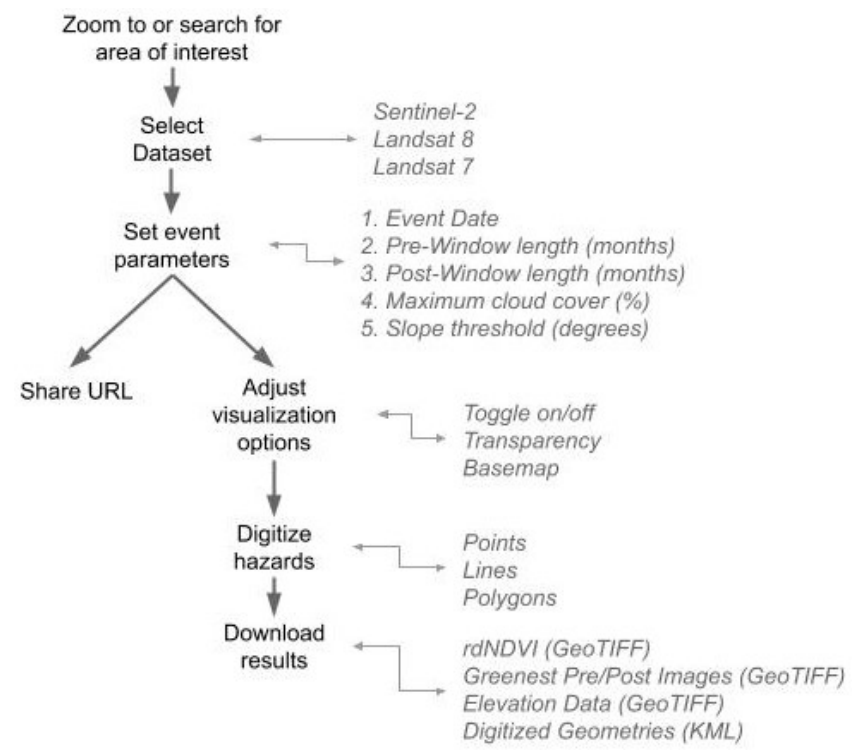

Figure 2. Suggested HazMapper workflows, including a branching point to share the URL or continue with analysis. Workflow culminates in downloading geographic tagged image file format (GeoTIFF) files suitable for input into a GIS for advanced analysis or visualization functions. If the user digitizes key areas of interest or hazards such as mass-wasting processes, burn, or inundation extents, these can be exported as KML files for sharing or viewing in Google Earth.

highest normalized difference vegetation index (NDVI) result, or the "greenest" pixel (Eq. 1).

$\mathrm{NDVI}=\left(\frac{\mathrm{NIR}-\mathrm{Red}}{\mathrm{NIR}+\mathrm{Red}}\right)$,

where NIR is the near-infrared response and Red is the visible red response.
HazMapper relies on a relative difference in the NDVI technique (rdNDVI, Eq. 2). Instead of differencing truecolor composites (i.e., red-green-blue bands), HazMapper exploits changes in surface vegetation by developing and differencing an NDVI band from the greenest-pixel composite images:

$\operatorname{rdNDVI}=\left(\frac{\mathrm{NDVI}_{\text {post }}-\mathrm{NDVI}_{\text {pre }}}{\sqrt{\mathrm{NDVI}_{\text {pre }}+\mathrm{NDVI}_{\text {post }}}}\right) \times 100$,

where $\mathrm{NDVI}_{\text {pre }}$ and $\mathrm{NDVI}_{\text {post }}$ are the NDVI images of the pre- and post-event greenest-pixel composites, respectively.

The results of the processing routine indicate a normalized percentage of the NDVI gained or lost. The normalization parameter includes $\mathrm{NDVI}_{\text {pre }}$ to account for pixels that had a low NDVI value before the event (e.g., existing mass-wasting scars, urban areas). The metric follows Norman and Christie (2020), who propose this method for addressing fractional pixels, where the NDVI signal response of vegetation is not consistent across a single pixel (e.g., both forest and grasses) and the non-linear responsiveness of the NDVI. Results may exceed $\pm 100 \%$. rdNDVI results of $<-100 \%$ are possible due to the ability of VIR to increase to greater than the NIR value, causing a polarity change of the NDVI. Results illustrate areas of the landscape that have either gained (increase in NDVI pixel values) or lost (decrease in NDVI pixel values) vegetation across the event as constrained by the preevent-window and post-event-window date ranges. For visualization purposes, HazMapper applies a color scale within the domain of $-50 \%$ to $+50 \%$, simplifying the analysis to highlight areas with vegetative loss or gain. Additionally, an inspector tool allows a user to click anywhere within the map domain, upon which a latitude-longitude coordinate pair and the rdNDVI pixel value will be returned interactively to the user. 
The three resulting data layers (greenest-pixel composite from pre- and post-event and rdNDVI) and a Shuttle Radar Topography Mission (SRTM)-derived $30 \mathrm{~m}$ resolution hillshade layer (for areas between $60^{\circ} \mathrm{N}$ and $60^{\circ} \mathrm{S}$ latitude) are added to the standard Google Earth Engine layer pane. These layers can be toggled on/off and their transparency modified with a slider to help with visualization.

Digitization of areas of interest from the map domain, for example, debris flow initiation sites, landslide extents, or potential wildfire burn areas, can be recorded using Google's default mapping tools. Points, lines, and polygons may be digitized in one or multiple layers. During download from HazMapper, these digitized geometries can be saved as a keyhole markup language (KML) file for viewing in Google Earth or sharing among an emergency response team or between research colleagues.

HazMapper includes an example panel in the lower left of the tool, pointing the user to five real-world natural hazard case studies (Fig. 1). The panel is intended to serve as a learning platform for new users to work with curated examples to explore these events.

Additional sharing of HazMapper results is made available via the use of variable tags within the URL. During usage of the tool, URL tags for the required event parameters are updated. Sharing of the updated link with a colleague or research partner allows that person to open HazMapper to the same viewport and updates the map function to the same event parameters. For the case studies discussed here, we have utilized the North Carolina State University Go Links URL service. For example, https:/go.ncsu.edu/ hazmapper-kenya (last access: 29 April 2021) directs the user to the curated example of rainfall-triggered debris flows located in West Pokot County, Kenya, in November 2019 (see Sect. 4.1.1). All case studies discussed in this paper are available pre-loaded from the HazMapper launch screen, under the "Show Examples" tab, or as direct URL links (see "Code and data availability").

Data download is an important component of HazMapper. This function allows for further analysis of processing results, including incorporation into emergency operation mapping platforms and advanced scientific analysis or visualization. The user can download the (1) rdNDVI image, (2) preevent and (3) post-event greenest-pixel composite images, (4) elevation and hillshade images derived from the global $30 \mathrm{~m}$ SRTM dataset, and/or (5) any user-digitized geometries delineating points or areas of interest. Raster data layers are distributed in geographic tagged image file format (GeoTIFF) and digitized geometries in KML.

\section{Results - case study examples}

The five curated examples included in the example panel (lower left of tool) are discussed herein. The intent of these case studies is not to provide an exhaustive analysis of the events but to showcase various applications of a rdNDVI cloud-computing method.

\subsection{Mass wasting}

Landslide events are a primary contributor to topographic erosion and landscape evolution (Korup et al., 2010), make available significant rock-bound and organic (soil and aboveground biomass) carbon for global biogeochemical cycling (Hilton et al., 2008), and caused at least 55997 non-seismic landslide fatalities between 2004-2016 and billions (USD) in global losses and damaged-infrastructure costs (Froude and Petley, 2018; Emberson et al., 2020; Kirschbaum et al., 2015; Petley, 2012). In the United States alone, annual losses to mass-wasting events exceed USD 3 billion (Spiker and Gori, 2003; Burns, 2007).

A significant amount of research has been performed on remotely detecting mass-wasting events such as debris flows, debris slides, or rock slides (Kirschbaum et al., 2019; Amatya et al., 2019; Mondini et al., 2011; Lu et al., 2019; Huang et al., 2020; Tsai et al., 2010; Yang et al., 2013). Pixel-based or object-oriented analysis (OOA) methods rely on characterizing change to the Earth surface via multi-spectral satellite imagery and correlating these changes to mass-wasting events (e.g., Lu et al., 2019). Recognizing that in forested areas, landslides denude the landscape of vegetation, NDVI change detection methods have been used for identifying landslides in many mid-latitude regions (Huang et al., 2020; Tsai et al., 2010; Mondini et al., 2011; Lu et al., 2019; Yang et al., 2013).

\subsubsection{Rainfall-triggered debris flows, West Pokot County, Kenya, 23 November 2019}

In middle to late November 2019, regions in eastern Africa experienced many days of intense rainfall. West Pokot County, Kenya, located in the rugged terrain of the East African Rift valley in western Kenya (Fig. 3), received more than $400 \mathrm{~mm}$ of rainfall within the period 23-25 November (Huffman et al., 2014). This rainfall event triggered failures of steep, soil-mantled hillslopes along the western rim of the East African Rift valley (Elgeyo Escarpment), initiating fatal debris flows that destroyed homes, agricultural fields, and infrastructure.

As early as 4 December 2019 (11 d following the masswasting event), Sentinel-2 images with limited cloud cover were available, and HazMapper was utilized to locate the debris flows (Fig. 3; see Supplement). In addition to the location of debris flows, the rdNDVI also captured riparian vegetation loss and sedimentation along the banks of lower-gradient rivers as they drained the mountainous terrain where the mass wasting occurred. Agricultural harvesting and planting activities are also apparent in the rdNDVI results, evident by their position on low-relief terrain outside of the drainage channels (Fig. 3D). 

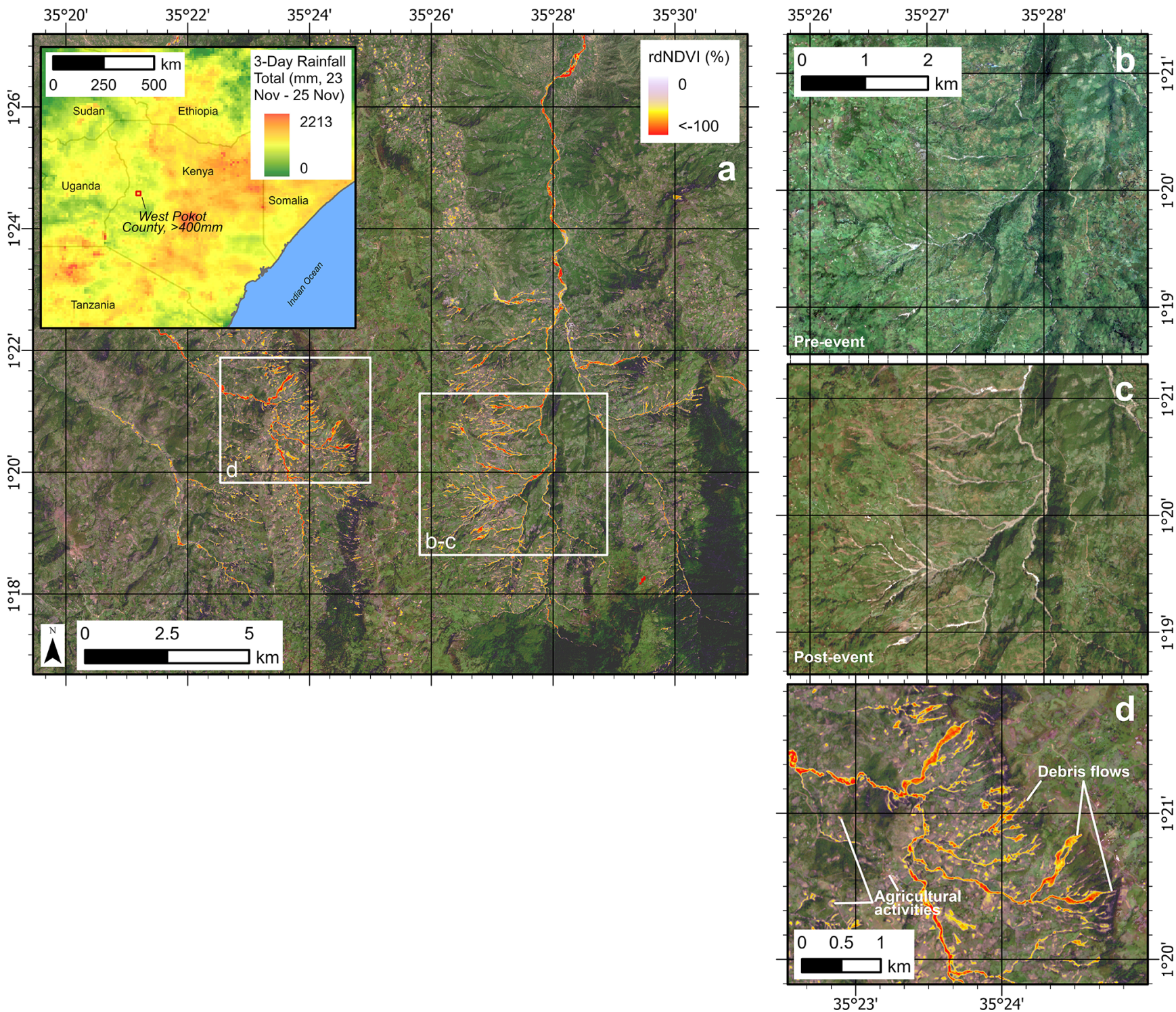

Figure 3. rdNDVI change detection images and greenest-pixel composites following the 23 November 2019 rainfall-induced mass-wasting event in West Pokot County, Kenya. See inset map for location and $3 \mathrm{~d}$ rainfall totals from storm, courtesy of NASA Integrated MultisatellitE Retrievals for GPM (IMERG) program. Parameters - dataset: Sentinel-2; event date: 23 November 2019; pre-window: 2 months; post-window: 0.5 months; maximum cloud cover: $30 \%$; slope threshold: $0^{\circ}$. West Pokot County received $>400 \mathrm{~mm}$ of rain in the $72 \mathrm{~h}$ period 23-25 November, triggering landslides, debris flows, and floods during the heaviest rainfall on 23 November. (a) rdNDVI illustrates hillslope and low-order stream channel disturbance, leading to debris flows on the upper slopes and vegetation loss and sedimentation along river channels flowing toward the north and northwest. Landscape change is easier to interpret with rdNDVI compared to observations based only on pre- and post-event color images (b and $\mathbf{c}$ ). Base image is post-event. (b) Pre-event greenest-pixel composite image showing relatively green vegetative cover across landscape. (c) 0.5 -month post-event greenest-pixel composite illustrates reduction in vegetation in landslide and debris flow tracks and along-river trunk channel. This reduction in vegetation is noted by negative rdNDVI values as seen in (a). (d) Close-up detail of negative rdNDVI values associated with mass wasting. Rectilinear patches of negative rdNDVI values in western area of (d) illustrate agricultural clearing or harvest activities across the event parameters. In mass-wasting applications, further use of slope thresholding and interpretation based on landscape morphology will reduce these undesired rdNDVI artifacts. User interpretation of output rdNDVI polygon areas is always warranted in order to minimize unwanted artifacts. Panels (b) and (c) have the same map scale. Panels (a) and (d) have the same rdNDVI color scale. rdNDVI and greenest-pixel composite data exported from HazMapper, available at https://go.ncsu.edu/hazmapper-kenya (last access: 29 April 2021). 


\subsubsection{Seismically triggered mass wasting, Southern Highlands, Papua New Guinea, $M_{\mathrm{w}}$ 7.5, 25 February 2018}

On 25 February 2018, a $M_{\mathrm{w}} 7.5$ earthquake struck the Southern Highlands of Papua New Guinea (PNG) along the Papuan Fold and Thrust Belt (Wang et al., 2019), triggering thousands of mass-wasting events, damming the Tagari River, and impacting numerous communities across the region. Over a span of 2 months, five aftershocks of $M_{\mathrm{w}}>6$ struck the same region (Wang et al., 2019). Nearly 3 years after the event, a published mass-wasting inventory is not available. Fatalities from coseismic mass wasting can be up to an order of magnitude greater than fatalities resulting from the earthquake itself (Budimir et al., 2014). The 2018 Papua New Guinea earthquake and associated mass wasting resulted in at least 160 fatalities (Wang et al., 2019), but the individual contributions (e.g., building collapse, burial by hillslope mass movements) are not well understood on account of this event occurring in a rural and remote part of the country.

Seismic shaking is a primary triggering mechanism for mass movement mobilization on steep mountain terrain. Coseismic mass wasting, therefore, strongly influences erosional budgets of mountain belts (Hovius et al., 1997; Keefer, 1994; Korup et al., 2010; Hilton et al., 2008). Keefer (2002) has demonstrated an empirical relationship based upon a global dataset between the moment magnitude of a mainshock and the maximum distance from the epicenter that seismically induced landslides are likely to be observed for the entire earthquake sequence (including aftershocks). For this $M_{\mathrm{w}} 7.5$ earthquake, the corresponding predicted maximum distance is approximately $300 \mathrm{~km}$. HazMapper was utilized to rapidly assess regions within several tens of kilometers from the epicenter, and hundreds of slides and flows were located (Fig. 4). Additional mass wasting was noted when expanding the analysis window to the predicted $300 \mathrm{~km}$ maximum distance based on the earthquake magnitude. Furthermore, we noted possible coseismic slides and flows as far as several hundred kilometers west of the epicenter in the Maoke Mountains of Indonesia. Mass wasting is common in the region, and these events could have unique triggers (e.g., rainfall triggered). However, restricting pre- and postevent time windows to as little as 2 months bracketing the $M_{\mathrm{w}} 7.5$ mainshock demonstrates consistent timing with the 25 February 2018 earthquake.

Due to difficulties in ascertaining high-temporalresolution sequences of mass-wasting events following seismic shaking, it is typically difficult to determine if particular events were triggered by just the mainshock or also by aftershocks. Thus, research to date has focused on earthquake sequences, inclusive of all associated shaking (e.g., Keefer, 2002). HazMapper allows researchers to temporally constrain landscape change and, in certain circumstances, may be useful for understanding hillslope failure sequences for large earthquakes that may include landslide-inducing aftershocks. Future research should consider utilizing these time-stamped change detection images to understand the progression of failures during an earthquake sequence.

While identifying vegetation loss for locating geohazards is a key characteristic of a mass-wasting event response, identifying subsequent vegetation recovery can serve as a proxy for the reduction in associated hazard (Shen et al., 2020). Simple modifications to event parameters in HazMapper, for example by changing the "event date" to a time after the occurrence of the disturbance event, can aid in observing vegetation recovery in landslide scars, suggesting establishment and growth of early successional species like grasses and shrubs (Fig. 4D). These stabilizing root masses buttress further soil loss and erosion and, thus, decrease the associated downslope sediment transport from the zone of mass wasting.

\subsection{Wildfire}

Wildfire experts have been utilizing multi-temporal, multispectral imagery to evaluate burn extents following wildfires since at least the launch of the Landsat thematic mapper program in 1984 (Keeley, 2009; Miller and Thode, 2007; Cocke et al., 2005). Multi-spectral indices such as the popular normalized burn ratio (NBR) and its derivatives (e.g., difference, relative difference) are widely employed to assess ecosystem impacts following a wildfire (Miller and Thode, 2007; Cocke et al., 2005). Discussion and debate about the most appropriate multi-spectral index to utilize for understanding fire impacts in wildland fire science are ongoing (Keeley, 2009; Miller and Thode, 2007; Escuin et al., 2008; Amos et al., 2019). The rdNDVI technique (Eq. 2) utilized in HazMapper is one such index (Norman and Christie, 2020).

\subsubsection{Chimney Tops 2 fire, Tennessee, USA, November 2016}

In the autumn of 2016, the southern Appalachian Mountains experienced drought conditions that contributed to dozens of wildfires that totaled some 75000 acres (30 351 ha; Andersen and Sugg, 2019). Originating within Great Smoky Mountains National Park (GRSM), the Chimney Tops 2 fire was first discovered on 23 November 2016 (National Park Service, 2017; Jiménez et al., 2018). The fire initially ignited on top of the north spire of Chimney Tops inside GRSM (Guthrie et al., 2017). Unexpected wind conditions facilitated the rapid expansion of the fire perimeter, and fires were noted inside the city limits of Gatlinburg, Tennessee, $10 \mathrm{~km}$ from the ignition point, by 28 November (National Park Service, 2017; Guthrie et al., 2017). The Chimney Tops 2 fire burned some 17000 acres (6880 ha) before eventually merging with other eastern Tennessee wildfires (Guthrie et al., 2017). Impacts from the fire included 14 fatalities, 14000 evacuations, over 2500 structures lost, and an estimated USD 2 billion in dam- 


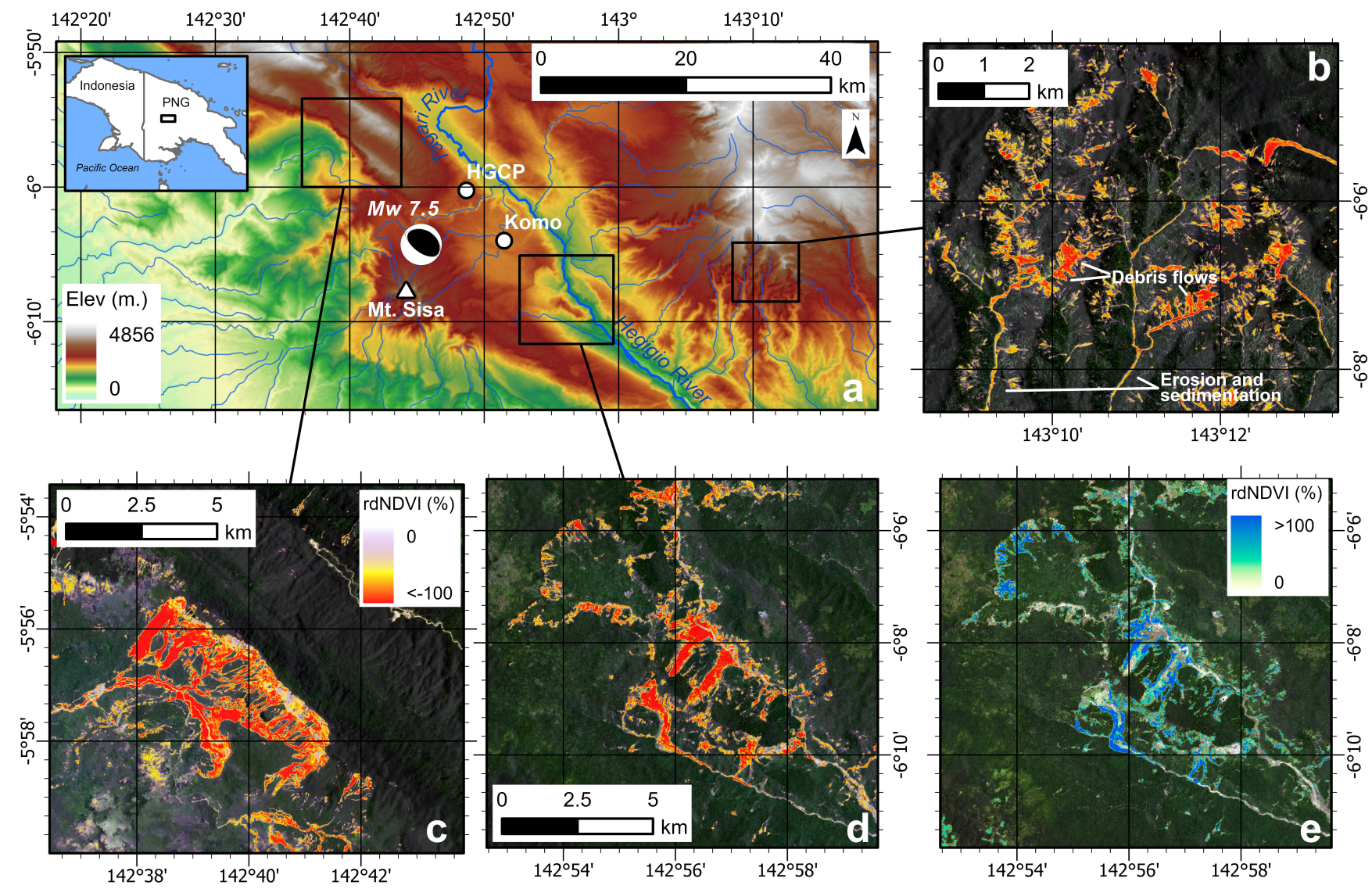

Figure 4. rdNDVI change detection images and greenest-pixel composites following a landsliding event triggered by the $M_{\mathrm{W}} 7.5$ earthquake on 26 February 2018 in the Southern Highlands of Papua New Guinea (PNG). Inset map shows location within the country. Parameters for (a-d) - dataset: Sentinel-2; event date: 25 February 2018; pre-window: 12 months; post-window: 9 months; maximum cloud cover: $30 \%$; slope threshold: $0.05^{\circ}$. (a) Elevation map for the Southern Highlands of PNG with epicenter (focal mechanism) plotted. HGCP is Hides Gas Conditioning Plant, an ExxonMobil liquefied natural gas facility. Komo is the nearest large town, and Mt. Sisa is a stratovolcano to the south. (b-d) Select areas with high mass-wasting density. Base images are the pre-event greenest-pixel composite, and (b-d) have the same rdNDVI color scale. (e) Recovery change detection image illustrating increases in vegetation within areas of previous mass wasting. These increases in vegetation are expected to increase root mass and provide a stabilizing effect for exposed soils. Parameters - dataset: Sentinel-2; event date: 26 August 2018; pre-window: 6 months; post-window: 6 months; maximum cloud cover: $30 \%$; slope threshold: $0.05^{\circ}$. rdNDVI and greenest-pixel composite data exported from HazMapper, available at https://go.ncsu.edu/hazmapper-png (last access: 29 April 2021).

age, and it was the largest wildland fire in recorded history in the park (National Park Service, 2017; Guthrie et al., 2017).

HazMapper was utilized to observe vegetation loss and, by proxy, the severity and burn extent (Fig. 5). In addition to the simple fire perimeter, the HazMapper method also illustrates burn severity by way of the rdNDVI, highlighting that the most severe burn, as indicated by greater-percent rdNDVI decreases, occurred along ridges and upper elevations, consistent with typical wildland fire behavior (Teie, 2018).

Following the identification of vegetation loss, subsequent post-fire vegetative re-greening of the landscape is depicted as the rdNDVI increases. Figure 5B and $\mathrm{C}$ illustrate recovery between the first and second growing seasons following the fire (2017 to 2018) and from the first through the third growing seasons (2017 to 2019), respectively. Forest recov- ery monitoring via remote sensing data is not a novel approach (Chen et al., 2014; Cuevas-González et al., 2009); however, the rapidity of observing the recovery via an openaccess remote-processing and cloud-based platform is, to our knowledge, novel.

\subsection{Volcanic eruptions}

Between 1600 and 2010 CE, 533 volcanic events have resulted in at least 278880 fatalities (Auker et al., 2013). The number of fatalities each year attributable to volcanic events is increasing with time (Auker et al., 2013), suggesting that as a species, we are not overcoming the danger associated with volcanic hazards. Volcanologists began using remote sensing tools, particularly multi-spectral satellite data, as early as the mid-1980s to monitor volcanic heat signa- 

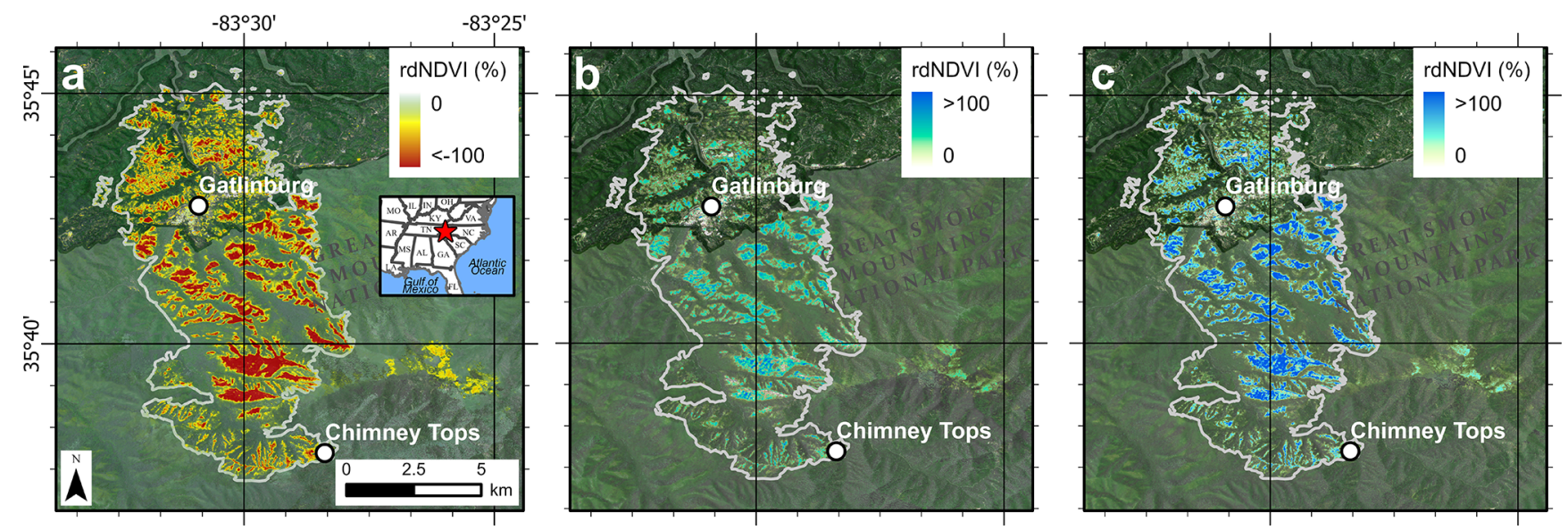

Figure 5. rdNDVI change detection images of vegetation loss and recovery during and following the Chimney Tops 2 fire that impacted Gatlinburg, Tennessee, USA, and surrounding communities in November-December 2016 (see location map to right). (a) rdNDVI illustrates vegetative loss during the fire. Gray line is the 6936 ha (17 140 acres) published extent of the burn (USGS, 2020). Note the preferential vegetative loss (burn) along ridgetops. Base image is pre-event. Parameters - event date: 13 December 2016; pre-window: 12 months; post-window: 9 months. (b) Change detection image of rdNDVI illustrating vegetative recovery between the first (2017) and second (2018) growing seasons following the fire. Base image is post-event. Parameters - event date: 13 December 2017; pre-window: 12 months; postwindow: 12 months. (c) Vegetative recovery (rdNDVI) between the first (2017) and third (2019) growing seasons following the fire. Note the general pattern of continuation and expansion of re-greening of the landscape, indicated by generally higher rdNDVI values (blues). Base image is post-event. Parameters - event date: 13 December 2017; pre-window: 12 months; post-window: 24 months. For all panels dataset: Sentinel-2; maximum cloud cover: $30 \%$; slope threshold: $0^{\circ}$. rdNDVI and greenest-pixel composite data exported from HazMapper, available from https://go.ncsu.edu/hazmapper-chimneytops (last access: 29 April 2021).

tures as precursors to eruptive activity (Rothery et al., 1988). More recently, synthetic aperture radar data aid in monitoring ground deformation associated with magmatic intrusions or eruptions (Hooper et al., 2004). The MODIS multi-spectral sensor is commonly used to monitor thermal characteristics and to detect volcanic eruptions (Wright et al., 2002); however, its variable 250 -to- $1000 \mathrm{~m}$ pixel size inhibits the use of the platform for adequately identifying many downslope hazards associated with eruptions. Downslope hazards may include lava flows, ballistic projectiles, pyroclastic flows, and lahars (Blong, 1984). Following eruptions, HazMapper's use of $30 \mathrm{~m}$ Landsat or $10 \mathrm{~m}$ Sentinel-2 data is well suited to identifying the spatial extent of these hazards, which may be only meters to tens of meters wide (e.g., a lahar track) and may travel many kilometers from the volcano.

\subsubsection{Pyroclastic flows - Volcán de Fuego, Antigua, Guatemala, 3 June 2018}

Volcán de Fuego is a subduction zone stratovolcano located in southwestern Guatemala, near the city of Antigua. Since 1524, Fuego has produced 51 eruptions with a volcanic explosivity index $\geq 2$ (Global Volcanism Program, 2013). The volcano is renowned for its consistent low-intensity Strombolian eruptions punctuated by larger, more violent, subPlinian eruption cycles (Naismith et al., 2019). The most recent eruptive cycle of Fuego, ongoing since 2015, consists of an increase in paroxysmal eruptions and resulting downs- lope hazards (Naismith et al., 2019). The 3-5 June 2018 sub-Plinian eruption generated pyroclastic flows in excess of $11 \mathrm{~km}$ in length, resulted in hundreds of fatalities, and destroyed the rural community of San Miguel Los Lotes (Pardini et al., 2019; Naismith et al., 2019).

HazMapper was utilized to observe landscape change following the 3-5 June 2018 Volcán de Fuego eruption (Fig. 6). Summit effects of the eruption are observed via HazMapper, as well as pyroclastic flows down the west, south, and east flanks of the stratovolcano for up to $11 \mathrm{~km}$. Due to Fuego's consistent eruptive activity and loose, steep, volcanic sediments, vegetation is generally sparse near the summit (Fig. 6B). However, as indicated by the rdNDVI results, loss of the limited vegetation was evident in $30 \mathrm{~m}$ Landsat data. Pyroclastic flows from the 3-5 June 2018 eruption are evident in the main valleys draining away from the volcano. Riparian vegetation loss and sedimentation was noted for $>60 \mathrm{~km}$ to the south-southwest from the volcano, and in one case, this impact was observed as far as the confluence with the Pacific Ocean (Fig. 6A).

\subsubsection{Effusive lava flows - lower east rift zone (LERZ), Kilauea Volcano, Hawaii, USA, May-September 2018}

Kîlauea is a basaltic shield volcano built from lavas derived from deep-mantle-driven processes. The magma feeding the volcano is distributed through a network of shallow rift struc- 

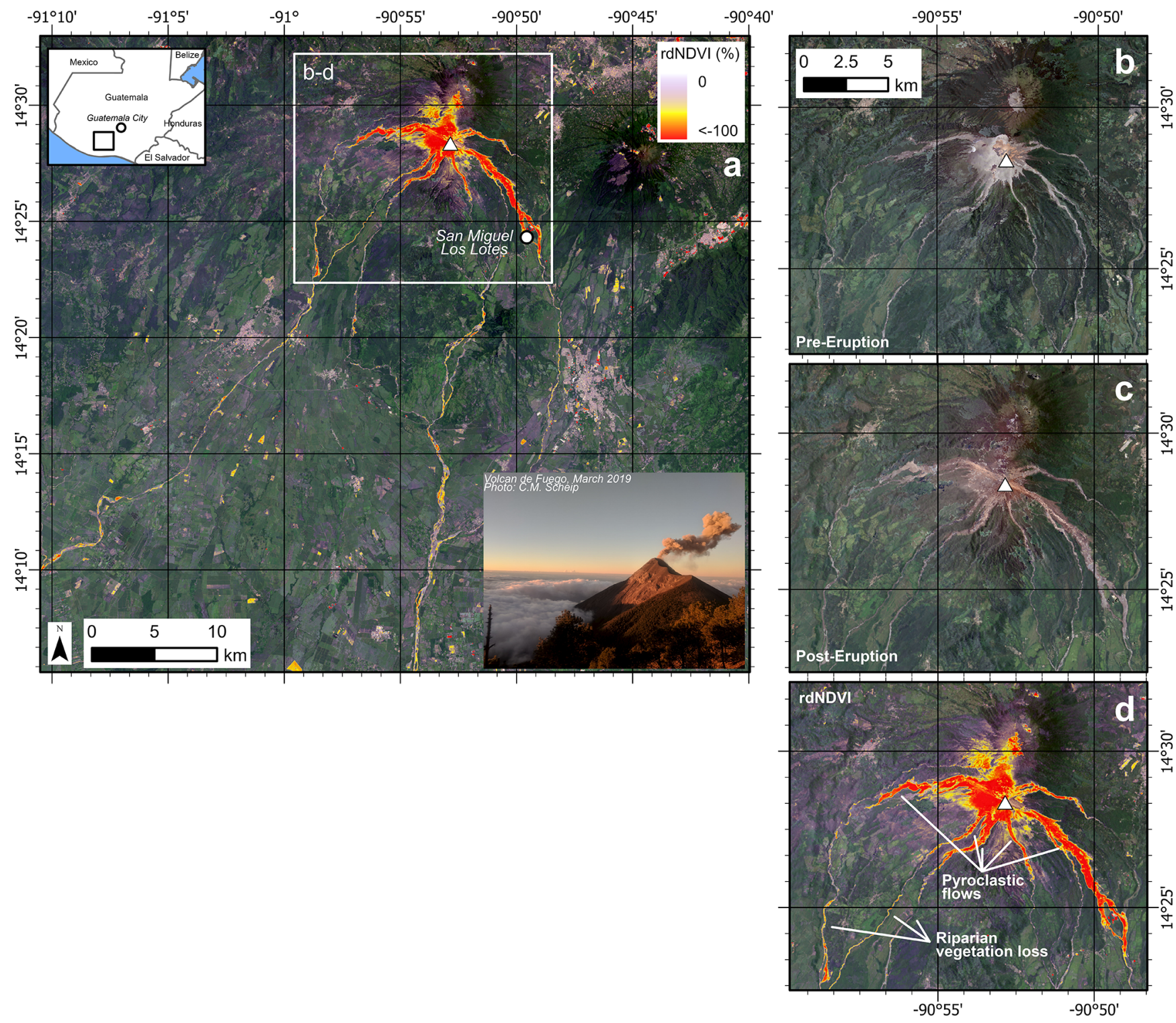

Figure 6. rdNDVI change detection images and greenest-pixel composites following the 3-5 June 2018 volcanic eruption of Volcán de Fuego $40 \mathrm{~km}$ southwest of Guatemala City, Guatemala. White triangle denotes summit. Parameters - dataset: Landsat 8 ; event date: 3 June 2018; pre-window: 12 months; post-window: 3 months; maximum cloud cover: $30 \%$; slope threshold: $0.05^{\circ}$. (a) rdNDVI across the event illustrates loss of vegetation on upper flanks of the volcano summit and influence of pyroclastic flows on volcano flanks and downstream areas. San Miguel Los Lotes is a small community on the southeastern flanks of Volcán de Fuego that was heavily impacted during the eruption, including at least 25 fatalities. Note significant riparian vegetation loss in channels flowing south to southwest away from volcano. Base image is post-eruption. (b-d) Close-up detail of Volcán de Fuego. (b) Pre-eruption greenest-pixel composite image of volcano. Note the limited vegetation near the summit. (c) Detailed image of volcano summit post-eruption greenest-pixel composite. A typical color composite pre-post comparison can be performed to locate areas impacted by the eruption and resulting pyroclastic flows, however, rdNDVI as shown in (d) provides a more rapid approach to identifying impacted areas and adds additional detail such as riparian vegetation loss that is more difficult to observe in a standard (RGB) color image comparison. (d) rdNDVI of the volcano following the eruption with notable observations annotated. Panels (b-d) have the same scale. Panels (a) and (d) use the same rdNDVI color scale. rdNDVI and greenest-pixel composite data exported from HazMapper, available at https://go.ncsu.edu/hazmapper-fuego (last access: 29 April 2021). 
tures and was pooled in a lava lake at its summit until commencement of the 2018 eruptive sequence. Eruptive characteristics have varied through time including a combination of periods of summit and/or rift eruptions and caldera collapse, infill, and overflow (Holcomb, 1987). The most recent 2018 caldera collapse-rift eruption sequence was well captured by a dense array of scientific instrumentation and social networking, adding significant information to our present understanding of the Kîlauea complex (Neal et al., 2019). The 2018 event culminated in the inundation of $35.5 \mathrm{~km}^{2}$ of Hawaii's Big Island and the destruction of hundreds of homes. Fortunately, there are no known fatalities from the event, likely due to the slow-moving nature of the eruption and the significant resources applied during the disaster management response efforts.

HazMapper was utilized to observe surface changes within the lower east rift zone (LERZ) following the cessation of the rift flank eruption sequence (Fig. 7). Utilizing $30 \mathrm{~m}$ Landsat data, the observed vegetation loss extending east and southeast from the LERZ approximates the published flow field from the 2018 eruption (Hawaiian Volcano Observatory staff, 2018). Efforts to utilize HazMapper to monitor the advance of the lava flows were hindered due to persistent cloud cover and volcanic gas emissions during the eruption. Additionally, the east-southeast extents of the lava flows generated additional landmass off the coast of Hawaii, but with no vegetation to lose, this landscape change was not detected using HazMapper.

The 2018 Kîlauea eruption response benefited from significant resource application by way of the existing Hawaiian Volcano Observatory and the associated resources of the US federal and Hawaii state governments and associated scientific and resource protection agencies. This example, therefore, is highlighted to perform a first-order comparison of the kind of results available with HazMapper, a free and openaccess toolset, to an on-the-ground effort with significant financial, personnel, equipment, and computing resources and attention (Fig. 7). For eruptions with less global attention or in more remote regions, remote sensing results like those available with HazMapper alone may approximate lava flow inundation extents, guiding future response efforts or scientific research around the event. Furthermore, the utilization of a consistent analysis platform between many eruptions may aid in volcanic research globally.

\section{Discussion}

\subsection{Limitations}

In the era of big data and cloud computing, a utility like HazMapper increases the pace at which researchers can evaluate global natural hazards. However, as with any analysis platform, limitations exist. The most important limitation of HazMapper, at present, is that the platform is neither an au-

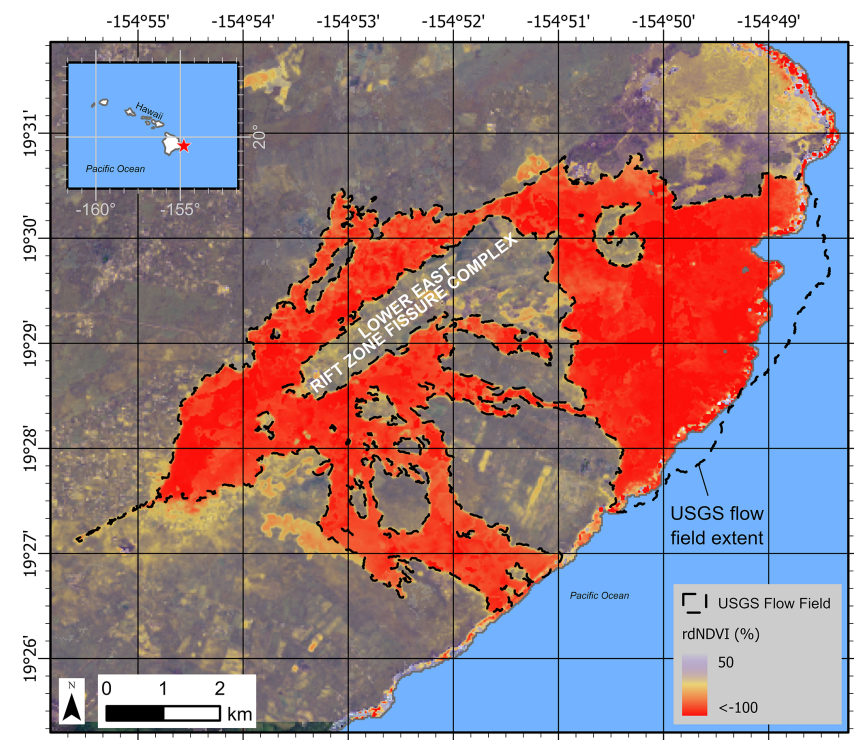

Figure 7. rdNDVI change detection images and greenest-pixel composites following 3 May-4 September 2018 lower east rift zone eruption of Kīlauea Volcano, Hawaii, USA. Parameters - dataset: Landsat 8; event date: 4 September 2018; pre-window: 12 months; post-window: 6 months; maximum cloud cover: $30 \%$; slope threshold: $0.05^{\circ}$. rdNDVI across the event illustrates loss of vegetation. Base image is post-eruption. Dashed black line is the published extent of the lava flow field (Hawaiian Volcano Observatory staff, 2018) for comparison to the HazMapper result. Notice the additional landmass added to the island by the eruption that is encapsulated by the lava flow perimeter polygon. Because there was no vegetation in this area before and after the eruption, the rdNDVI method does not account for the new landmass. In future analyses, however, we expect to be able to identify vegetation growth on the landmass. rdNDVI and greenest-pixel composite data exported from HazMapper, available at https://go.ncsu.edu/hazmapper-lerz (last access: 29 April 2021).

tomated nor a semi-automated routine. The platform does not predict where landslides have occurred or what areas were burned during a wildfire, for example. Instead, the platform computes a very simple vegetation-based metric, which in many cases can be indicative of a natural disaster. As such, no accuracy assessments or omission-commission errors are included in the case studies presented here. HazMapper does, however, provide a solid platform for the development and use of future semi-automation routines for various natural disasters. Augmentation and testing of user-driven semi-automation techniques utilizing machine learning for landslide identification in HazMapper are in the developmental stage and will be discussed in a future paper.

The underlying datasets in HazMapper allow users to constrain the timing of an event to $\geq 5 \mathrm{~d}$ (Sentinel-2) or $\geq 16 \mathrm{~d}$ (Landsat). Imagery is typically available on Google Earth Engine (GEE) within approximately $24 \mathrm{~h}$ of collection by the satellite. Recognizing that during natural disasters, commu- 
nity impacts can undergo many developments in this time frame, differences in pre- and post-event images may require some interpretation and cannot provide a day-by-day account of ground conditions. This must be considered in the context of alternative approaches, however. Traditional remote sensing studies often rely on single pre- and post-event images. In these cases, it is an assumption of the analyst that the impacts occurred during the event being studied. For example, if a landslide is present in a post-event single image but not a pre-event single image, it is often assumed that the landslide occurred during the particular event under consideration (e.g., Huang et al., 2020; Lu et al., 2019).

The timing of suitable datasets for an initial evaluation of disaster impacts will depend on the timing of an event relative to acquisition schedules of the Sentinel-2 or Landsat platforms, atmospheric conditions (e.g., cloud cover during or following a rainfall-triggered mass-wasting event or smoke from long-burning wildfires), and seasonal considerations. Acquisition schedules are publicly available for both platforms and can be used in conjunction with HazMapper to help responders understand when suitable datasets may become available. Even if the imagery is not clear (e.g., cloudy, obscured by aerosols), performing the analysis generally takes seconds and, because of the URL-update feature, provides a URL that can be saved offline and re-executed when new data are posted. Events that occur in the winter in temperate environments can be difficult to discern because there is minimal healthy green vegetation to lose during a disaster. In these cases, observing change in the pre- and post-event color composite images may be helpful; however, analysis following the spring green-up of the landscape will often provide a more complete understanding of impacts.

HazMapper only accesses datasets publicly hosted within the Google Earth Engine Data Catalog. While many researchers have the funding to pursue the use of datasets acquired on a near-daily basis (e.g., from Planet Labs, Inc.), HazMapper currently does not have a mechanism for ingesting these data.

Two final limitations relate to the spatial extent of processing and data downloads. Even with the large amounts of computational power available with the platform, continentalscale analysis is typically not feasible. Long wait times for data or their failure to load in HazMapper commonly results when the user is trying to evaluate too large an area. Zooming in will initiate reprocessing and data will usually begin to load. Similarly, current external user downloads (e.g., users of the application) are limited to $32 \mathrm{MB}$ by Google. This is approximately $400 \mathrm{~km}^{2}$ with Sentinel-2 (10 m pixel size) data. HazMapper utilizes the entire view extent within the user's browser window when the download routine is initialized. If the area is larger than $\sim 400 \mathrm{~km}^{2}$, the download window may not appear. If this occurs, the user should zoom in to a larger scale.

With all of these limitations, it is important to recognize that Google is regularly making improvements and modifica- tions to Earth Engine. We intend to monitor these activities and update the HazMapper application as needed to mesh with future changes to Earth Engine.

\subsection{Use of the event parameters}

The event parameters window is designed to allow flexibility in analysis for various natural disaster types, geographies, and objectives. The combination of the GUI layout and URL updating is designed to promote rapid analysis of events with different parameter combinations to best understand the natural disaster. Event parameters are defined in Table 1, and details regarding their usage are provided here:

- Dataset. This parameter allows the user to determine which dataset (Landsat 7, Landsat 8, or Sentinel-2) to use for analysis. The coarser resolution of the Landsat sensors (30 m) compared to the Sentinel sensors $(10 \mathrm{~m})$ is faster to process and is suitable for analysis of larger regions (e.g., Sect. 3.3.2). The higher-resolution Sentinel sensors are more applicable for identifying smaller features, such as narrow debris flow tracks). Landsat 7 is included in HazMapper to allow analysis of events that occurred as early as 1999. Following the May 2003 scan line corrector (SLC) mirror failure, individual Landsat 7 images exhibit striping; however, the greenestpixel compositing methods of HazMapper can be leveraged to mitigate these artifacts. By extending window lengths, these gaps are filled with data from subsequent overpasses. As an example, Fig. 8 evaluates erosion, vegetation removal, and sedimentation along a coastline of Indonesia following the 2004 Sumatra-Andaman seismogenic tsunami. A short-window-length (1-month pre- and post-event) analysis is obscured by striping. By extending the window lengths, these artifacts are reduced.

- Event date. The event date is intended for demarcating the pre- and post-event periods for which to perform the rdNDVI calculation. Generally this is a known value from the literature or news reports. However, by combining this field with imagery acquisition schedules, this parameter can also be used to determine the date of a natural disaster. Date estimates can only be made within the margin of error that is approximated by the sensor's acquisition, (e.g., within $5 \mathrm{~d}$ if using Sentinel-2 or within $16 \mathrm{~d}$ if using Landsat).

- Window lengths. Window lengths are measured in months and can be altered to capture more or fewer data before or after an event. This is useful when balancing the need for cloud-free imagery with a level of confidence in the timing of impacts from a natural disaster. For example, a small window length will allow the user to be confident in the timing of the natural disaster impacts. For vegetation loss studies, this con- 

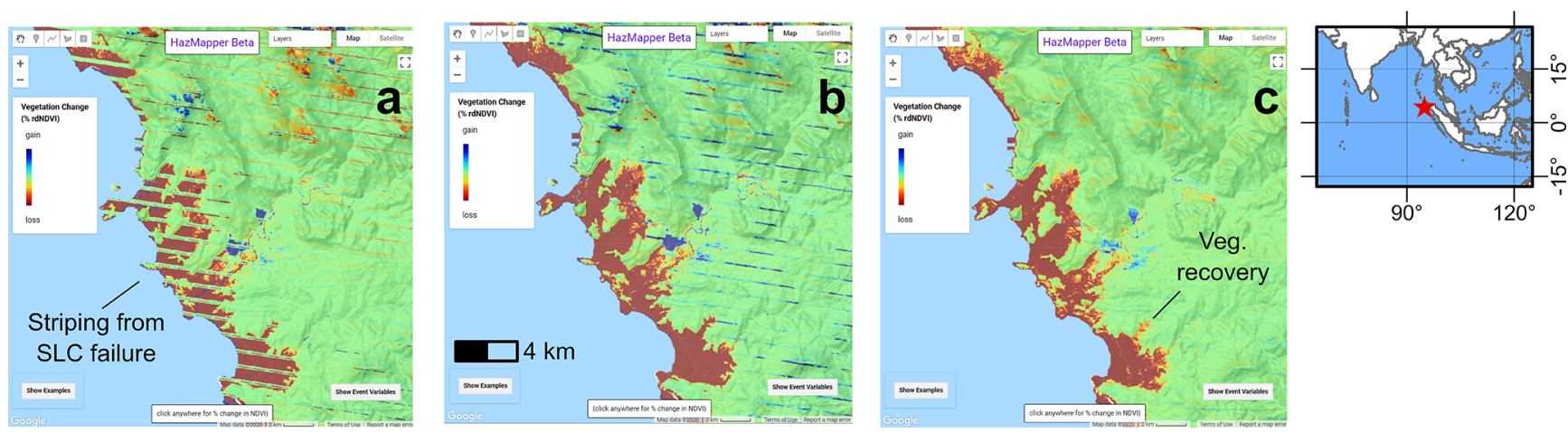

Figure 8. rdNDVI change detection images illustrate coastal erosion, vegetation removal, and sedimentation following the 26 December 2004 tsunami in Indonesia resulting from the Sumatra-Andaman earthquake. Parameters - dataset: Landsat 7; event date: 26 December 2004; maximum cloud cover: $100 \%$; slope threshold: $0.01^{\circ}$. Pre-windows: 1, 2, and 12 months; post-windows: 1, 2, and 12 months for (a), (b), and (c), respectively. rdNDVI across the event illustrates tsunami inundation zone and resulting loss in vegetation. Striping in the data from the scan line corrector failure in Landsat 7 is evident in a short-look window (e.g., 1 month, a), but these artifacts are reduced by increasing the pre- and post-event windows (b, c). By 12-month pre- and post-event periods (c), the striping is significantly reduced in results; however, vegetative recovery is also present in this longer post-event cycle that captures the first growing season following the tsunami. This example is accessible at https://go.ncsu.edu/hazmapper-indonesia-tsunami (last access: 29 April 2021).

fidence is driven by the pre-event window length. This is because of the greenest-pixel compositing technique, which always identifies the maximum-NDVI conditions in the given analysis window. For example, the preevent window length in the Kenya debris flow example (Sect. 3.1.1, Fig. 3) temporally constrains the debris flows to have occurred within the 2-month period preceding the event date of 23 November $2019( \pm 5 \mathrm{~d}$, consistent with the acquisition rate of Sentinel-2). Combining this result with news reports, interviews, or other local knowledge of the region can increase confidence that the major debris flow swarm imaged in HazMapper was a result of the 23 November 2019 storms.

- Maximum cloud cover. The intent of this parameter is to increase processing speed by omitting any images with cloud cover greater than the parameter value. For example, if the user is confident there will be images with very low cloud cover, a value such as $30 \%$ maximum cloud cover will only perform the cloud filtering and NDVI calculations on those images with cloud-cover parameters of less than $30 \%$. This will also yield the cleanest results, because even the cloud filters utilized in Earth Engine can result in some peripheral noise in the composite or NDVI images.

- Slope threshold. This minimum slope value for analysis is used to mask out areas of low slope during the visualization process. This can be very useful to remove water bodies (e.g., lakes, oceans) which are often noisy and can distract from rdNDVI targets. Similarly, this can be used to mask out low-slope areas, like wide valley bottoms, while processing an area for mass-wasting events.

\subsection{Further applications}

HazMapper may be useful in many other types of studies beyond those described here. For example, vegetation can be a proxy for decreasing hazard following large mass-wasting events (Shen et al., 2020; Yunus et al., 2020). By altering the parameters in HazMapper, this regrowth can be tracked and quantified, e.g., Fig. 4D. Additional applications include characterizing agricultural or logging operations (including tracking illegal operations), monitoring controlled burns and the growth of early successional species, or biological blight monitoring.

\subsection{Future work}

There are several anticipated development opportunities for HazMapper. Principal among these is the development of hazard-specific platforms to provide more focused analysis for various hazard types. For example, a mass-wasting platform could incorporate pixel segmentation, consideration of developed areas, and slope thresholds. Further research into the application of HazMapper in arid or snow-covered environments, including the consideration of snow-related indices (i.e., normalized difference snow index, NDSI), is ongoing and may be helpful for detecting mass-wasting events in non-vegetated, high-latitude, or high-elevation regions. A wildfire platform can be expanded to include burn-specific indices such as the NBR. And for all platforms, various change detection methods (e.g., shortwave infrared differencing) should continue to be evaluated. Radar data bring exciting opportunities, and as radar processing routines become available within GEE, they should be leveraged (e.g., Handwerger et al., 2020). 
Future development of HazMapper will leverage new datasets as they become available. The initial release includes options to analyze Sentinel-2, Landsat 8 , and Landsat 7 datasets. HazMapper's underlying source code is designed to easily incorporate multi-spectral imagery data from forthcoming missions, such as Landsat 9 that is anticipated to launch in September 2021 (McCorkel et al., 2018).

\section{Conclusions}

HazMapper is a free and open-access application developed in Google Earth Engine. It is primarily tailored to observing vegetated-landscape change as a proxy for natural hazard impacts. The approach is novel, leveraging the power of Google Earth Engine to democratize change detection from multispectral satellite imagery in a user interface designed for researchers, emergency responders, and the scientifically curious public. HazMapper does not require users to download any datasets; possess a background in data analysis, software development, or coding; or have access to specialized software other than an internet browser. And because processing occurs remotely, low-powered computers (e.g., Google Chromebooks), tablet computers, and even smartphones are suitable for use with HazMapper, although the small screen size of such devices is a limitation.

In version 1.0 of HazMapper, a single toolset is released for the observation of surface vegetation loss by way of a relative difference in NDVI values, suggesting the extents of hillslope and channelized mass wasting, wildfires, pyroclastic flows, and lava inundation areas. This is not a semi-automated method, and HazMapper does not predict areas of natural disasters. Instead, the platform currently makes rdNDVI calculations accessible and performs them rapidly, increasing the pace at which researchers can evaluate events. HazMapper is an open-source project, and community contributions are welcomed. Supporting JavaScript source code for HazMapper is available at https://doi.org/10.5281/zenodo.4103348.

Code and data availability. Source code is available under a research-only license at https://doi.org/10.5281/zenodo.4103348 (Scheip and Wegmann, 2020). Examples discussed in this article or presented in figures can be accessed from the following URLs:

- rainfall-triggered mass wasting, West Pokot County, Kenya, 23 November 2019 - https://go.ncsu.edu/hazmapper-kenya (last access: 29 April 2021)

- seismically triggered mass wasting, Southern Highlands, Papua New Guinea, $M_{\mathrm{W}}$ 7.5, 25 February 2018 - https://go. ncsu.edu/hazmapper-png (last access: 29 April 2021)

- Chimney Tops 2 wildfire, Tennessee, USA, November 2016 - https://go.ncsu.edu/hazmapper-chimneytops (last access: 29 April 2021)
- pyroclastic flows, Volcán de Fuego, Antigua, Guatemala, 3 June 2018 - https://go.ncsu.edu/hazmapper-fuego (last access: 29 April 2021)

- lower east rift zone eruption, Kīlauea Volcano, Hawaii, USA, May-September 2018 - https://go.ncsu.edu/hazmapper-lerz (last access: 29 April 2021)

- tsunami inundation, Indonesia, 26 December 2004 https://go.ncsu.edu/hazmapper-indonesia-tsunami (last access: 29 April 2021).

Supplement. The supplement related to this article is available online at: https://doi.org/10.5194/nhess-21-1495-2021-supplement.

Author contributions. CMS and KWW contributed to the design and execution of building HazMapper, including the source code and this paper. Both authors gave final approval of this paper.

Competing interests. The authors declare that no competing interests are present.

Special issue statement. This article is part of the special issue "Remote sensing and Earth observation data in natural hazard and risk studies". It is not associated with a conference.

Acknowledgements. We gratefully acknowledge Steve P. Norman of the USDA Forest Service Southern Research Station in Asheville, North Carolina, for helpful early conversations regarding the mathematics behind the rdNDVI techniques. Additional thanks are owed to Jesse Hill of the North Carolina Geological Survey for helpful discussions regarding the use of the rdNDVI technique in observing debris flows in western North Carolina and for his input on the HazMapper user interface. The comments and suggestions of the three anonymous reviewers assisted in the improvement of the initial submission.

Review statement. This paper was edited by Michelle Parks and reviewed by three anonymous referees.

\section{References}

Abancó, C., Bennett, G. L., Matthews, A. J., Matera, M. A., and Tan, F. J.: The role of geomorphology, rainfall and soil moisture in the occurrence of landslides triggered by 2018 Typhoon Mangkhut in the Philippines, Nat. Hazards Earth Syst. Sci. Discuss. [preprint], https://doi.org/10.5194/nhess-2020-259, in review, 2020.

Amatya, P., Kirschbaum, D., and Stanley, T.: Use of very highresolution optical data for landslide mapping and susceptibility analysis along the Karnali highway, Nepal, Remote Sens., 11, 2284, https://doi.org/10.3390/rs11192284, 2019. 
Amos, C., Petropoulos, G. P., and Ferentinos, K. P.: Determining the use of Sentinel-2A MSI for wildfire burning \& severity detection, Int. J. Remote Sens., 40, 905-930, https://doi.org/10.1080/01431161.2018.1519284, 2019.

Andersen, L. M. and Sugg, M. M.: Geographic multi-criteria evaluation and validation: A case study of wildfire vulnerability in Western North Carolina, USA following the 2016 wildfires, Int. J. Disast. Risk. Re., 39, 101123, https://doi.org/10.1016/j.ijdrr.2019.101123, 2019.

Ashley, S. T. and Ashley, W. S.: Flood fatalities in the United States, J. Appl. Meteorol. Clim., 47, 805-818, https://doi.org/10.1175/2007JAMC1611.1, 2008.

Auker, M. R., Stephen, R., Sparks, J., Siebert, L., Crosweller, H. S., and Ewert, J.: A statistical analysis of the global historical volcanic fatalities record, Journal of Applied Volcanology, 2, 1-24, https://doi.org/10.1186/2191-5040-2-2, 2013.

Blong, R.: Volcanic Hazards, 424 pp., Academic Press, Sydney, Australia, 1984.

Brand, B. D., Schlegel, M., and McMullin-Messier, P.: "Map Your Hazards!": Assessing Hazards, Vulnerability, and Risk Through an Active Learning-Based Educational Module, in: Interdisciplinary Teaching About Earth and the Environment for a Sustainable Future, 213-231, Springer, Basel, Switzerland, 2019.

Budimir, M. E., Atkinson, P. M., and Lewis, H. G.: Earthquakeand-landslide events are associated with more fatalities than earthquakes alone, Nat. Hazards, 72, 895-914, https://doi.org/10.1007/s11069-014-1044-4, 2014.

Burns, S.: February 2007 - Prevention Is the Best Medicine, available at: http://www.geotimes.org/feb07/feature_prevention.html (last access: 1 April 2021), 2007.

Cando-Jácome, M. and Martínez-Graña, A.: Determination of primary and secondary lahar flow paths of the Fuego Volcano (Guatemala) using morphometric parameters, Remote Sens., 11, 727, https://doi.org/10.3390/rs11060727, 2019.

Chen, W., Moriya, K., Sakai, T., Koyama, L., and Cao, C.: Monitoring of post-fire forest recovery under different restoration modes based on time series Landsat data, Eur. J. Remote Sens., 47, 153168, https://doi.org/10.5721/EuJRS20144710, 2014.

Cocke, A. E., Fulé, P. Z., and Crouse, J. E.: Comparison of burn severity assessments using Differenced Normalized Burn Ratio and ground data, Int. J. Wildland Fire, 14, 189-198, https://doi.org/10.1071/WF04010, 2005.

Cuevas-González, M., Gerard, F., Balzter, H., and Riaño, D.: Analysing forest recovery after wildfire disturbance in boreal Siberia using remotely sensed vegetation indices, Glob. Change Biol., 15, 561-577, https://doi.org/10.1111/j.13652486.2008.01784.x, 2009.

Emberson, R., Kirschbaum, D., and Stanley, T.: New global characterisation of landslide exposure, Nat. Hazards Earth Syst. Sci., 20, 3413-3424, https://doi.org/10.5194/nhess-203413-2020, 2020.

Escuin, S., Navarro, R., and Fernández, P.: Fire severity assessment by using NBR (Normalized Burn Ratio) and NDVI (Normalized Difference Vegetation Index) derived from LANDSAT TM/ETM images, Int. J. Remote Sens., 29, 1053-1073, https://doi.org/10.1080/01431160701281072, 2008.

Froude, M. J. and Petley, D. N.: Global fatal landslide occurrence from 2004 to 2016, Nat. Hazards Earth Syst. Sci., 18, 2161-2181, https://doi.org/10.5194/nhess-18-2161-2018, 2018.
Gallen, S. F., Clark, M. K., Godt, J. W., Roback, K., and Niemi, N. A.: Application and evaluation of a rapid response earthquake-triggered landslide model to the 25 April 2015 $M_{\mathrm{W}} 7.8$ Gorkha earthquake, Nepal, Tectonophysics, 714-715, 173-187, https://doi.org/10.1016/j.tecto.2016.10.031, 2017.

Global Volcanism Program: Fuego (342090) in Volcanoes of the World, v. 4.8.6., edited by: Venzke, E., Smithsonian Institution, downloaded 26 February 2020, https://doi.org/10.5479/si.GVP.VOTW4-2013, 2013.

Goetz, J. N., Brenning, A., Petschko, H., and Leopold, P.: Evaluating machine learning and statistical prediction techniques for landslide susceptibility modeling, Computers and Geosciences, 81, 1-11, https://doi.org/10.1016/j.cageo.2015.04.007, 2015.

Gold, R. D.: A comparative study of aerial photographs and LiDAR imagery for landslide detection in the Puget Lowland, Washington, Washington Division of Geology and Earth Resources Open File Report 2004-6, 66 pp., available at: https://www.dnr.wa.gov/ Publications/ger_ofr2004-6_landslide_detection_study.zip (last access: 2 February 2020), 2004.

Gorelick, N., Hancher, M., Dixon, M., Ilyushchenko, S., Thau, D., and Moore, R.: Google Earth Engine: Planetary-scale geospatial analysis for everyone, Remote Sens. Environ., 202, 18-27, https://doi.org/10.1016/j.rse.2017.06.031, 2017.

Green, G. M. and Sussman, R. W.: Deforestation history of the eastern rain forests of Madagascar from satellite images, Science News Series, 248, 212-215, https://doi.org/10.1126/science.248.4952.212, 1990.

Guthrie, V., Finucane, M., Keith, P., and Stinnett, D.: After Action Review of the November 28, 2016, Firestorm, p. 164, available at: http://wildfiretoday.com/documents/AAR_ ChimneyTops2.pdf (last access: 29 April 2021), 2017.

Guzzetti, F., Reichenbach, P., Ardizzone, F., Cardinali, M., and Galli, M.: Estimating the quality of landslide susceptibility models, Geomorphology, 81, 166-184, https://doi.org/10.1016/j.geomorph.2006.04.007, 2006.

Handwerger, A. L., Jones, S. Y., Huang, M.-H., Amatya, P., Kerner, H. R., and Kirschbaum, D. B.: Rapid landslide identification using synthetic aperture radar amplitude change detection on the Google Earth Engine, Nat. Hazards Earth Syst. Sci. Discuss. [preprint], https://doi.org/10.5194/nhess-2020-315, 2020.

Hansen, M., Potapov, P., Moore, R., Hancher, M., Turubanova, S., Tyukavina, A., Thau, D., Stehman;, S., Goetz, S., Loveland, T., Kommareddy, A., Egorov, A., Chini, L., Justice, C., and Townshend, J.: High-Resolution Global Maps of 21st-Century Forest Cover Change, Science, 342, 850-853, https://doi.org/10.1126/science.1244693, 2013.

Hawaiian Volcano Observatory staff: Preliminary map of the 2018 lower East Rift Zone eruption of Kīlauea Volcano, Island of Hawai'i, U.S. Geological Survey, https://doi.org/10.5066/P994OGY8, 2018.

Hilton, R. G., Galy, A., and Hovius, N.: Riverine particulate organic carbon from an active mountain belt: Importance of landslides, Global Biogeochem. Cy., 22, 1-12, https://doi.org/10.1029/2006GB002905, 2008.

Hoffman, J. P., Shaffer, S., and Perkovic-Martin, D.: NASA L-SAR instrument for the NISAR (NASA-ISRO) Synthetic Aperture Radar mission, Earth Observing Missions and Sensors: Development, Implementation, and Characterization IV, 9881, 988108, https://doi.org/10.1117/12.2228489, 2016. 
Holcomb, R. T.: Eruptive history and long-term behavior of Kilauea Volcano (Hawaii), Volcanism in Hawaii, 1, 261-350, USGS Professional Paper 1350, Washington, D.C., 1987.

Holzer, T. L. and Savage, J. C.: Global earthquake fatalities and population, Earthq. Spectra, 29, 155-175, https://doi.org/10.1193/1.4000106, 2013.

Hooper, A., Zebker, H., Segall, P., and Kampes, B.: A new method for measuring deformation on volcanoes and other natural terrains using InSAR persistent scatterers, Geophys. Res. Lett., 31, 23, https://doi.org/10.1029/2004GL021737, 2004.

Hovius, N., Stark, C. P., and Allen, P. A.: Sediment flux from a mountain belt derived by landslide mapping, Geology, 25, 231-234, https://doi.org/10.1130/00917613(1997)025<0231:SFFAMB>2.3.CO;2, 1997.

Huang, Q., Wang, C., Meng, Y., Chen, J., and Yue, A.: Landslide Monitoring Using Change Detection in Multitemporal Optical Imagery, IEEE Geosci. Remote S., 17, 312-316, https://doi.org/10.1109/LGRS.2019.2918254, 2020.

Huffman, G., Bolvin, D., Braithwaite, D., Hsu, K., Joyce, R., and Xie, P.: Integrated Multi-satellitE Retrievals for GPM (IMERG), NASA's Precipitation Processing Center, Version 4.4, available at: https://gpm.nasa.gov/data (last access: 24 January 2020), 2014.

Jiménez, P. A., Muñoz-Esparza, D., and Kosović, B.: A high resolution coupled fire-atmosphere forecasting system to minimize the impacts of wildland fires: Applications to the Chimney Tops II wildland event, Atmosphere, 9, 197, https://doi.org/10.3390/atmos9050197, 2018.

Keefer, D. K.: The importance of earthquake-induced landslides to long-term slope erosion and slope-failure hazards in seismically active regions, Geomorphology, 10, 265-284, https://doi.org/10.1016/b978-0-444-82012-9.50022-0, 1994.

Keefer, D. K.: Investigating landslides caused by earthquakes - A historical review, Surv. Geophys., 23, 473-510, https://doi.org/10.1023/A:1021274710840, 2002.

Keeley, J. E.: Fire intensity, fire severity and burn severity: A brief review and suggested usage, Int. J. Wildland Fire, 18, 116-126, https://doi.org/10.1071/WF07049, 2009.

Kirschbaum, D., Stanley, T., and Zhou, Y.: Spatial and temporal analysis of a global landslide catalog, Geomorphology, 249, 415, https://doi.org/10.1016/j.geomorph.2015.03.016, 2015.

Kirschbaum, D., Watson, C. S., Rounce, D. R., Shugar, D. H., Kargel, J. S., Haritashya, U. K., Amatya, P., Shean, D., Anderson, E. R., and Jo, M.: The State of Remote Sensing Capabilities of Cascading Hazards Over High Mountain Asia, Front. Earth Sci., 7, 197, https://doi.org/10.3389/feart.2019.00197, 2019.

Korup, O., Densmore, A. L., and Schlunegger, F.: The role of landslides in mountain range evolution, Geomorphology, 120, 77-90, https://doi.org/10.1016/j.geomorph.2009.09.017, 2010.

Langhorst, T., Pavelsky, T. M., Frasson, R. P. d. M., Wei, R., Domeneghetti, A., Altenau, E. H., Durand, M. T., Minear, J. T., Wegmann, K. W., and Fuller, M. R.: Anticipated improvements to river surface elevation profiles from the surface water and ocean topography mission, Front. Earth Sci., 7, 1-13, https://doi.org/10.3389/feart.2019.00102, 2019.

Lauer, D. T., Morain, S. A., and Salomonson, V. V.: The landsat program: Its origins, evolution, and impacts, Photogramm. Eng. Rem. S., 63, 831-838, 1997.
Lu, P., Qin, Y., Li, Z., Mondini, A. C., and Casagli, N.: Landslide mapping from multi-sensor data through improved change detection-based Markov random field, Remote Sens. Environ., 231, 111235, https://doi.org/10.1016/j.rse.2019.111235, 2019.

Malamud, B. D., Turcotte, D. L., Guzzetti, F., and Reichenbach, P.: Landslide inventories and their statistical properties, Earth Surf. Proc. Land., 29, 687-711, https://doi.org/10.1002/esp.1064, 2004.

Masek, J. G., Lindsay, F. E., and Goward, S. N.: Dynamics of urban growth in the Washington DC metropolitan area, 1973-1996, from Landsat observations, Int. J. Remote Sens., 21, 3473-3486, https://doi.org/10.1080/014311600750037507, 2000.

McCorkel, J., Montanaro, M., Efremova, B., Pearlman, A., Wenny, B., Lunsford, A., Simon, A., Hair, J., Reuter, D., Goddard, N., and Flight, S.: LANDSAT 9 Thermal Infrared Sensor 2 Characterization Plan Overview, IGARSS 2018 2018 IEEE International Geoscience and Remote Sensing Symposium, 8845-8848, 22-27 July 2018, Valencia, Spain, https://doi.org/10.1109/IGARSS.2018.8518798, 2018.

Meentemeyer, R., Rizzo, D., Mark, W., and Lotz, E.: Mapping the risk of establishment and spread of sudden oak death in California, Forest Ecol. Manag., 200, 195-214, https://doi.org/10.1016/j.foreco.2004.06.021, 2004.

Miller, J. D. and Thode, A. E.: Quantifying burn severity in a heterogeneous landscape with a relative version of the delta Normalized Burn Ratio (dNBR), Remote Sens. Environ., 109, 66-80, https://doi.org/10.1016/j.rse.2006.12.006, 2007.

Mondini, A. C., Guzzetti, F., Reichenbach, P., Rossi, M., Cardinali, M., and Ardizzone, F.: Semi-automatic recognition and mapping of rainfall induced shallow landslides using optical satellite images, Remote Sens. Environ., 115, 1743-1757, https://doi.org/10.1016/j.rse.2011.03.006, 2011.

Naismith, A. K., Matthew Watson, I., Escobar-Wolf, R., Chigna, G., Thomas, H., Coppola, D., and Chun, C.: Eruption frequency patterns through time for the current (1999-2018) activity cycle at Volcán de Fuego derived from remote sensing data: Evidence for an accelerating cycle of explosive paroxysms and potential implications of eruptive activity, J. Volcanol. Geoth. Res., 371, 206219, https://doi.org/10.1016/j.jvolgeores.2019.01.001, 2019.

National Park Service: Chimney Tops 2 Fire Review Individual Fire Review Report, p. 116, available at: https://www.wildfirelessons.net/orphans/viewincident? DocumentKey $=5 \mathrm{bfa} 19 \mathrm{~b} 8-\mathrm{ca} 1 \mathrm{e}-4 \mathrm{f} 4 \mathrm{a}-882 \mathrm{f}-9 \mathrm{dad} 173 \mathrm{ec} 28 \mathrm{c}$ (last access: 29 April 2021), 2017.

Neal, C., Brantley, S., Antolik, L., Babb, J., Burgess, M., Calles, K., Cappos, M., Chang, J., Conway, S., Desmither, L., Dotray, P., Elias, T., Fukunaga, P., Fuke, S., Johanson, I., Kamibayashi, K., Kauahikaua, J., Lee, R., Pekalib, S., Miklius, A., Million, W., Moniz, C., Nadeau, P., Okubo, P., Parcheta, C., Patrick, M., Shiro, B., Swanson, D., Tollet, W., Trusdell, F., Younger, E., Zoeller, M., Montgomery-Brown, E., Anderson, K., Poland, M., Ball, J., Bard, J., Coomb, M., Dietterich, H., Kern, C., Thelen, W., Cervelli, P., Orr, T., Houghton, B., Gansecki, C., Hazlett, R., Lundgren, P., Diefenbach, A., Lerner, A., Waite, G., Kelly, P., Clor, L., Werner, C., Mulliken, K., Fisher, G., and Damby, D.: The 2018 rift eruption and summit collapse of Kîlauea Volcano, Science, 363, 367-374, 2019.

Norman, S. P and Christie, W. M: Satellite-based evidence of forest stress and decline across the conterminous United States for 
2016, 2017, and 2018, Gen. Tech. Rep. SRS-250. Asheville, NC: US Department of Agriculture, Forest Service, Southern Research Station, 2020, 151-166, 2020.

Pardini, F., Queißer, M., Naismith, A., Watson, I. M., Clarisse, L., and Burton, M. R.: Initial constraints on triggering mechanisms of the eruption of Fuego volcano (Guatemala) from 3 June 2018 using IASI satellite data, J. Volcanol. Geoth. Res., 376, 54-61, https://doi.org/10.1016/j.jvolgeores.2019.03.014, 2019.

Paton, D. and Johnston, D.: Disasters and communities: vulnerability, resilience and preparedness, Disast. Prev. Manag., 10, 270277, https://doi.org/10.1108/EUM0000000005930, 2001.

Petley, D.: Global patterns of loss of life from landslides, Geology, 40, 927-930, https://doi.org/10.1130/G33217.1, 2012.

Rothery, D. A., Francis, P. W., and Wood, C. A.: Volcano monitoring using short wavelength infrared data from satellites, J. Geophys. Res., 93, 7993-8008, https://doi.org/10.1029/JB093iB07p07993, 1988.

Santi, P., Cannon, S., and DeGraff, J.: Wildfire and landscape change, chap. 13.16, Elsevier, Amsterdam, the Netherlands, 2013

Scheip, C. M. and Wegmann, K. W.: HazMapper v1.0 source code, Zenodo, https://doi.org/10.5281/zenodo.4103348, 2020.

Schneider, A.: Monitoring land cover change in urban and periurban areas using dense time stacks of Landsat satellite data and a data mining approach, Remote Sens. Environ., 124, 689-704, https://doi.org/10.1016/j.rse.2012.06.006, 2012.

Scholl, H. J. and Carnes, S. L.: Managerial challenges in early disaster response: The case of the 2014 Oso/SR530 landslide disaster, Proceedings of the International ISCRAM Conference, May 2017, 961-972, Albi, France, 2017.

Shen, P., Zhang, L. M., Fan, R. L., Zhu, H., and Zhang, S.: Declining geohazard activity with vegetation recovery during first ten years after the 2008 Wenchuan earthquake, Geomorphology, 352, 106989, https://doi.org/10.1016/j.geomorph.2019.106989, 2020.

Spiker, E. C. and Gori, P.: National landslide hazards mitigation strategy, a framework for loss reduction, 1244, US Geological Survey, 2003.

Teie, W. C.: Firefighter's Handbook on Wildland Firefighting: Strategy, Tactics, and Safety, Fire Protection Publications, 4 edn., Stillwater, OK, 2018.

Tillery, A. C. and Rengers, F. K.: Controls on debris-flow initiation on burned and unburned hillslopes during an exceptional rainstorm in southern New Mexico, USA, Earth Surf. Proc. Land., 45, 1051-1066, https://doi.org/10.1002/esp.4761, 2019.

Tsai, F., Hwang, J.-H., Chen, L.-C., and Lin, T.-H.: Post-disaster assessment of landslides in southern Taiwan after 2009 Typhoon Morakot using remote sensing and spatial analysis, Nat. Hazards Earth Syst. Sci., 10, 2179-2190, https://doi.org/10.5194/nhess10-2179-2010, 2010.
USGS: Landsat's View of South America's Wildfires, Earth Resources Observation and Science Center, available at: https://www.usgs.gov/centers/eros/ landsat-s-view-south-america-s-wildfires (last access: 15 January 2020), 2019.

USGS: US Geological Survey Geospatial Multi-Agency Coordination (GeoMAC) Wildland Fire Perimeters, data retrieved 21 February 2020 from USGS GeoMAC database, available at: https://rmgsc.cr.usgs.gov/outgoing/GeoMAC/, last access: 29 April 2020.

Wang, S., Xu, C., Li, Z., Wen, Y., and Song, C.: 7.5 Papua New Guinea earthquake: A possible complex multiple faults failure event with deep-seated reverse faulting Shuai Wang, Earth and Space Science, 0-2, e2019EA000966, https://doi.org/10.1029/2019EA000966, 2019.

Wegmann, K. W.: Digital landslide inventory for the Cowlitz County urban corridor, Washington, version 1.0, Washington Division of Geology and Earth Resources Report of Investigations 35, 24 pp. text, 14 maps, scale $1: 24,000$, available at: https: //fortress.wa.gov/dnr/geologydata/publications/ger_ri35.zip (last access: 29 April 20201), 2006.

Woodcock, C. E., Allen, R., Anderson, M., Belward, A., Bindschadler, R., Cohen, W., Gao, F., Goward, S. N., Helder, D., Helmer, E., Nemani, R., Oreopoulos, L., Schott, J., Thenkabail, P. S., Vermote, E. F., Vogelmann, J., Wulder, M. A., and Wynne, R.: Free Access to Landsat Imagery, Science, 320, 1011a-1011a, https://doi.org/10.1126/science.320.5879.1011a, 2008.

Wright, R., Flynn, L., Garbeil, H., Harris, A., and Pilger, E.: Automated volcanic eruption detection using MODIS, Remote Sens. Environ., 82, 135-155, https://doi.org/10.1016/S00344257(02)00030-5, 2002.

Xu, C., Xu, X., Tian, Y., Shen, L., Yao, Q., Huang, X., Ma, J., Chen, X., and Ma, S.: Two comparable earthquakes produced greatly different coseismic landslides: The 2015 Gorkha, Nepal and 2008 Wenchuan, China events, J. Earth Sci., 27, 1008-1015, https://doi.org/10.1007/s12583-016-0684-6, 2016.

Yang, W., Wang, M., and Shi, P.: Using MODIS NDVI time series to identify geographic patterns of landslides in vegetated regions, IEEE Geosci. Remote. S, 10, 707-710, https://doi.org/10.1109/LGRS.2012.2219576, 2013.

Yunus, A. P., Fan, X., Tang, X., Jie, D., Xu, Q., and Huang, R.: Decadal vegetation succession from MODIS reveals the spatiotemporal evolution of post-seismic landsliding after the 2008 Wenchuan earthquake, Remote Sens. Environ., 236, 111476, https://doi.org/10.1016/j.rse.2019.111476, 2020.

Zhou, L., Tucker, C. J., Kaufmann, R. K., Slayback, D., Shabanov, N. V., and Myneni, R. B.: Variations in northern vegetation activity inferred from satellite data of vegetation index during 1981 to 1999, J. Geophys. Res.-Atmos., 106, 20069-20083, https://doi.org/10.1029/2000JD000115, 2001. 